\title{
EDITORIAL
}

\section{What is this thing called somnolence?}

\section{Rodenstein}

I n 1929, Cole Porter composed, for a musical comedy, a song called "What Is This Thing Called Love?", which became a great classic in jazz music [1]. The musical comedy had a suggestive title, very appealing for modern pneumologists: Wake Up and Dream.

For many people suffering from obstructive sleep apnoea, we are able nowadays to help them to wake up refreshed, out of dreams or nightmares, and able to face the new day fully awake, fit to burst [2]. This is the usual result of sleeping with a mask connected to a continuous positive pressure device [3]. However, a small number of patients compliant to continuous positive airway pressure (CPAP) therapy, using it every night and all night, remain abnormally sleepy. They declare persistent severe somnolence and fatigue [4,5]. In this issue of the European Respiratory Journal, VERNET et al. [6] present the results of an extraordinary effort to dissect, define and identify what causes somnolence in these patients. They studied 20 patients with CPAP-treated obstructive sleep apnoea and persistent complains of daytime sleepiness and fatigue, and compared them with 20 other well-matched patients that had no residual sleepiness, and to 20 matched normal subjects. They made every possible effort to exclude other known causes of daytime sleepiness and fatigue, from narcolepsy to restless leg syndrome, depression, behavioural sleep restriction, chronic use of sedative drugs, alcoholism, night shift work, and neurological and psychiatric diseases. Once they were sure that these patients had only obstructive sleep apnoea, they checked as far as possible that their symptoms were consistent and persistent (at least for the previous 6 months), and that CPAP treatment was applied as rigorously and completely as it was prescribed in both patient groups. It should be mentioned that these sleepy patients were not just sleepy. They were quite sleepy, as shown by a mean Epworth Sleepiness Score (ESS) $>16$. In addition, they complained of unrefreshing nights and persistent severe daytime fatigue.

All participants were submitted to three types of investigations in addition to complete neurological and clinical examinations, determinations of serum ferritin and class II human leukocyte antigen genotypes, and brain magnetic resonance imaging. All completed validated questionnaires for sleep symptoms, depression, anxiety, morningness, hyperactivity, fatigue and apathy. All participants were submitted to a $48-\mathrm{h}$ sleep monitoring, with a first full-night polysomnography followed by a multiple sleep latency test with five nap opportunities,

CORRESPONDENCE: D. Rodenstein, Service de pneumologie et Centre de médicine du sommeil, Cliniques universitaires Saint-Luc, Université catholique de Louvain, Avenue Hippocrate 10, Brussels 1200, Belgium. E-mail: rodenstein@pneu.ucl.ac.be then a second full-night polysomnography, followed by a sleep extension protocol the next day (participants were left in the dark and offered the possibility to sleep at will). Patients slept at all times with their own CPAP. Finally, all participants performed an extensive battery of cognitive tests.

The summary of the results is exceptionally short. Compared with both nonsleepy patients and to the group of normal subjects, sleepy patients had shorter (though still normal) sleep latencies, slightly less deep sleep (yet remarkably normal for people in their sixties), and more daytime (but similar 24-h) sleep time. Sleepy patients complained of significantly more somnolence and fatigue. They had higher depression scores (but had no clinical depression) and seemed to have less selfconfidence. Sleepy patients reported more memory problems in questionnaires (subjective data), yet they showed fewer errors on testing (objective results). Everything else was similar. Even what was different could perhaps become similar if a statistical adjustment is performed for multiple comparisons (which the authors did not perform). VERNET et al. [6] suggest that chronic intermittent hypoxia could have damaged various specific wake-active neurons, as shown in animal models [7]. They also state that the absence of clear differences (beyond complaints) between sleepy patients and the rest of the subjects could be due to an absence of sensitivity of the tests they used, or of symptoms being too mild. This is hardly the case for an ESS $>16$.

Anyone interested in the concept of somnolence should carefully read the work by VERNET et al. [6]. It represents a breathtaking effort to select a population as pure as possible, then to explore every conceivable aspect of the known or supposed causes of sleepiness. At the end of the journey, we have to accept that very little comes out. The authors state that the patients have persistent and severe chronic symptoms, whereby they feel something that the tests were unable to clearly identify. Finally, they hypothesise that these patients might be part of an extreme group of complainers. This is certainly worth exploring in future studies, especially considering the small number of patients with residual symptoms that could represent the very last part of a Gaussian curve of sensations, feelings and expressions [8].

One could postulate that there is no single concept of somnolence but that there are various (not to say infinite) types of sleepiness. The sleepiness of a normal human being after a long work day is very different from the sleepiness of a narcoleptic patient, or from that of an obstructive sleep apnoea patient, or that of a paid student participating in a sleep restriction physiology study. One patient may call sleepiness the inability to keep the eyes open; his fellow may refer to the 
inability to keep his attention focused, whereas for the next in line, sleepiness may be the willingness to sleep. Would they be identified by cognitive tests, symptomatic scores or objective sleep measurements? There has been no research on the quality of the descriptors of sleepiness in relation to the severity of sleep apnoea or the abnormality of sleep, as has been conducted on dyspnoea sensation [9].

Sleepiness is a perceived sensation. It is not the only one. Thirst is the perceived sensation of the need to drink. The physiology of thirst is perfectly understood, the mechanisms are known, and the afferent and efferent pathways are well identified. Yet, physiology alone can't explain why the intensity of thirst will differ between two individuals with the same physiological status. Beliefs on hydration effects may impact actual drinking as much as physiology [10]. Similarly, pain is another sensation where the perception not only depends on the physiology but also on the psychology of the individual subject. Studies on pain identified a particular way of feeling, perceiving, and affectively and behaviourally reacting to pain. Some individuals have a particularly bad relationship to pain, that contributes to an exaggerated pain perception for a given painful stimulation. This has been referred to as "catastrophising" [11]. Catastrophising increases pain and decreases useful coping reactions [12]. It is characterised by magnification, rumination and helplessness [13]. It has been postulated that catastrophising is not limited to pain, but will manifest itself in other problematic situations [11]. It is tempting to ask whether residual somnolence in adequately CPAP-treated patients with obstructive sleep apnoea is an expression of catastrophising.

One final remark concerns a curious finding. None of the sleepy patients had diabetes in the study by VERNET et al. [6]. This is not impossible in a small, 20-subject sample. Yet, it is unusual to find 20 obese patients with severe obstructive sleep apnoea and none of them be diabetic ( $25 \%$ of the nonsleepy patients were diabetics). Could diabetes protect from residual sleepiness, whatever its mechanism?

We should congratulate the authors on this extraordinary effort to better understand somnolence. Even if, just as Cole Porter didn't know what love was, we still don't fully know what sleepiness is, we can at least better identify, thanks to
VERNET et al. [6], what residual sleepiness in sleep apnoea is not.

\section{STATEMENT OF INTEREST}

A statement of interest for D. Rodenstein can be found at www.erj. ersjournals.com/site/misc/statements.xhtml

\section{REFERENCES}

1 Porter CA. What is this thing called love? Wake Up and Dream. 1929.

2 Giles TL, Lasserson TJ, Smith BJ, et al. Continuous positive airways pressure for obstructive sleep apnoea in adults. Cochrane Database Syst Rev 2006; 1: CD001106.

3 Sullivan CE, Issa FG, Berthon-Jones M, et al. Reversal of obstructive sleep apnoea by continuous positive airway pressure applied through the nares. Lancet 1981; 1: 862-865.

4 Santamaria J, Iranzo A, Montserrat JM, et al. Persistent sleepiness in CPAP treated obstructive sleep apnea patients: evaluation and treatment. Sleep Med Rev 2007; 11: 195-207.

5 Pepin JL, Viot-Blanc V, Escourrou P, et al. Prevalence of residual excessive sleepiness in CPAP-treated sleep apnoea patients: the French multicentre study. Eur Respir J 2009; 33: 1062-1067.

6 Vernet C, Redolfi S, Attali V, et al. Residual sleepiness in obstructive sleep apnoea: phenotype and related symptoms. Eur Respir J 2011; 38: 98-105.

7 Veasey SC, Davis CW, Fenik P, et al. Longterm intermittent hypoxia in mice: protracted hypersomnolence with oxidative injury to sleep-wake brain regions. Sleep 2004; 27: 194-201.

8 Stradling JR, Smith D, Crosby J. Post-CPAP sleepiness: a specific syndrome? J Sleep Res 2007; 16: 436-438.

9 Yorke J, Moosavi SH, Shuldham C, et al. Quantification of Dyspnoea using descriptors: developments and initial testing of the Dyspnoea-12. Thorax 2010; 65: 21-26.

10 Winger JM, Dugas JP, Dugas LR. Beliefs about hydration and physiology drive drinking behaviors in runners. Br J Sports Med 2010; [Epub ahead of print DOI: 10.1136/bjsm.2010.075275].

11 Sullivan MJL, Thorn B, Haythornwaite JA, et al. Theoretical perspectives on the relation between catastrophizing and pain. Clin J Pain 2001; 17: 52-64.

12 Keefe FJ, Brown GK, Wallston KA. Coping with rheumatoid arthritis: catastrophizing as a maladaptive strategy. Pain 1989; 37: 51-56.

13 Sullivan MJL, Bishop S, Pivik J. The pain catastrophizing scale: development and validation. Psychol Assess 1995; 7: 524-532. 